\title{
Uma discussão da matemática do professor que ensina matemática nos anos iniciais do ensino fundamental
}

\author{
Edivagner Souza dos Santos \\ Universidade Federal de Mato Grosso do Sul (UFMS) \\ vaguinho_souza@hotmail.com

\section{João Ricardo Viola dos Santos} \\ Universidade Federal de Mato Grosso do Sul (UFMS) \\ joao.santos@ufms.br
}

\section{Resumo}

Neste artigo apresentamos uma discussão da matemática do professor que ensina matemática nos anos iniciais do Ensino Fundamental. Para isso, tomamos como principal referência a noção de matemática do professor de matemática, apresentada por Romulo Lins (2006). Por meio de leituras de produções escritas de alunos e de diálogos entre alunos e professores em salas de aula de matemática, produzimos delineamentos a respeito da prática profissional do professor que ensina matemática nos anos iniciais. Nossas principais considerações são em relação à construção de repertórios com professores que ensinam matemática no Ensino Fundamental, para lerem e produzirem com as produções de significados matemáticos e não matemáticos de alunos.

Palavras-chave: Matemática do Professor de Matemática. Anos Iniciais do Ensino Fundamental. Modelo dos Campos Semânticos.

\section{A discussion of the mathematics of the mathematics teacher at the first years of the elementary school}

\begin{abstract}
This paper presents a discussion on the mathematics of the mathematics teachers at the first years of the Elementary Education. We consider as main reference the notion of the mathematics of the mathematics teacher, presented by Romulo Lins (2006). Through readings of written productions of students and dialogues between students and teachers in mathematics classrooms, we produced delineations on the professional practice of the mathematics teacher who teaches mathematics in the early years. Our principal considerations are in relation the building of repertories with mathematics teachers to they read and produce with student production of meaning mathematics and nomathematics
\end{abstract}


Keywords: Mathematics of the Mathematics Teacher. Elementary Education First Years. Model of Semantic Field.

\section{Introdução}

Nos livros de matemática ou em conversas entre professores que ensinam matemática, grande parte das discussões recaem sobre o conteúdo matemático. Como ensinar esse conteúdo? Quais dificuldades dos alunos para tal conteúdo? Qual importância desse conteúdo? Quais propostas didáticas são viáveis para ensinar esse conteúdo? Acreditamos que há uma limitação, um estreitamento ao tratar questões da prática profissional de professores que ensinam matemática, apenas do ponto de vista do conteúdo, visto que muitas outras coisas acontecem nas salas de aula. O foco no conteúdo, de certo modo, "esconde" particularidades e singularidades de processos de produção de significados que acontecem em sala de aula, tanto de alunos quanto de professores.

A dinâmica que envolve o trabalho do professor de matemática está diretamente ligada a múltiplos elementos que “jogam” certos jogos com a(s) matemática(s), sendo eles sociais, culturais, econômicos, não matemáticos, ficcionais. Estes elementos são construídos por meio de processos de produção de significados no interior de uma atividade ou situação. A sala de aula é um espaço em que múltiplos processos de produção de significados acontecem, mesmo que alguns deles sejam sorrateiros, devido à imposição da dinâmica de uma aula tradicional, em que o professor diz (e manda) o que deve e o que não deve ser feito e os alunos escutam (e obedecem) como devem pensar, escrever, resolver.

Se olharmos para a formação inicial e continuada de professores que ensinam matemática, em meio a essas considerações, poderíamos nos perguntar: Qual(is) matemática(s) o futuro professor precisa conhecer para ministrar "efetivamente" suas aulas na Educação Básica? Que tipos de discussões matemáticas devem fazer parte da formação inicial do professor? Qual a natureza desses conhecimentos e dessas discussões? Mesmo com muitas pesquisas realizadas nessa área (MOREIRA, 2004; LINARDI, 2006; LINS, 2006; BALL, 2008; VIOLA DOS SANTOS, LINS, 2016; BALL, BASS, 2003; BALL, THAMES, PHELPS, 2008; MA, 2009; ROWLAND, 2005, 2008), algumas respostas ainda necessitam ser discutidas e, talvez, sistematizadas para oferecer possibilidades para os professores em formação e em serviço.

Assim, neste artigo apresentamos uma discussão da matemática do professor que ensina matemática nos anos iniciais do Ensino Fundamental. Para isso, tomamos como principal referência 
a noção de matemática do professor de matemática apresentada por Romulo Lins (2006). Por meio de leituras de produções escritas de alunos e de diálogos entre alunos e professores em salas de aula de matemática, produzimos delineamentos a respeito da prática profissional do professor que ensina matemática nos anos iniciais.

Na primeira parte, apresentamos algumas discussões a respeito da Matemática do Professor de Matemática (LINS, 2006), tomando como pano de fundo algumas noções do Modelo dos Campos Semânticos (LINS, 1999; 2012). Na segunda, fazemos uma discussão de significados matemáticos e não matemáticos de produções escritas de alunos e de diálogos entre alunos e professores em salas de aula de matemática. Na terceira parte, produzimos delineamentos a respeito de aspectos da prática de professores que ensinam matemática.

\section{A Matemática do Professor de Matemática}

Lins (2006) tece considerações de situações corriqueiras de sala de aula e evidencia exemplos exemplares, como ele próprio enuncia, para caracterizar a matemática do professor de matemática. Esses exemplos, apesar de serem habituais e movimentarem processos de produção de significados matemáticos e não matemáticos, por vezes não são percebidos pelos professores. A partir disto, Lins (2006) argumenta em favor de uma leitura não centralizadora por parte dos professores, que não seja construída apenas do ponto de vista do conteúdo matemático e que não se prenda apenas aos conceitos matemáticos formais. Essa leitura pode ser realizada (sempre e apenas em tentativas) na busca de tentar colocar-se como um aluno, em tentar entender como ele opera, levando em consideração seu modo de lidar com palavras, noções, circunstâncias.

Nesse contexto, Lins (2006) apresenta noção da Matemática do Professor de Matemática (MPM), que se caracteriza por aceitar significados matemáticos e não matemáticos para o que chamamos de matemática. Este é um ponto central de nossa discussão e que se desdobrará nos exemplos e delineamentos. Talvez, deve ser proveitoso ressaltar que ao falarmos de significados matemáticos e não matemáticos, não temos o desejo de desprezar os significados matemáticos formais, mas sim apontar que na atividade do professor de matemática significados não matemáticos também estão presentes e têm forte influência nos modos de os alunos produzirem significados.

Em sala de aula é comum professores utilizarem certos artifícios para conduzir o aluno a entender determinado aspecto de um conceito ou ideia. Nesses processos, os professores utilizam significados não matemáticos, atribuindo a eles algum significado matemático, por exemplo, atribuir altura nula para uma folha de papel para representar uma figura plana, ou utilizar uma bola 
como algo em formato esférico, desprezando as saliências que ocorrem entre seus gomos, ou mesmo utilizar uma balança para estabelecer a ideia de igualdade matemática, ou ainda utilizar pedaços de pizzas para explicar fração. Se por um lado é comum os professores utilizarem esses significados em suas falas, por outro, quando os alunos produzem significados não matemáticos em suas resoluções, é habitual que eles sejam desprezados e ignorados pelo professor, por fugir do rigor matemático que os alunos 'deveriam' utilizar.

Diante deste impasse, dois pontos merecem destaque. O primeiro é que não importa o modo como o professor deseje que seus alunos pensem ou façam algo, ele simplesmente não pode (não consegue) antecipar o que eles vão produzir. Quando o aluno se coloca na posição de resolver um problema ou exercício, sua atividade/produção/ação lhe coloca na condição de autor daquele texto e, para ele, faz sentido fazer o que faz (LINS, 2006). O segundo trata-se de uma mudança de perspectiva do professor em seus modos de ler e produzir significados com os alunos, que incorpore significados matemáticos e não matemáticos. Neste aspecto, a MPM "permite que o professor incorpore, a diferentes partes de sua prática profissional, a aceitação de legitimidades de significados não matemáticos” (LINARDI, 2006, p. 42).

O "aceitar", aqui, não se refere a "aceitar como correto", mas, sim, a "aceitar como legítimo para o aluno" e, a partir disso, possibilitar uma interação produtiva. Caso contrário, a alternativa é simplesmente dizer que o aluno está errado e repetir para ele o que é certo. (LINARDI, 2006, p. 400)

O aluno é (ou deveria ser) o centro da prática profissional do professor que ensina matemática que tem por interesse construir interações em tentativas de ampliar modos de produção de significados (do aluno e dele). A MPM é um convite para produzir com o outro por meio das diferenças nos processos de produção de significado. Segundo Lins (2008, p. 543),

[...] é apenas no momento em que posso dizer "eu acho que entendo como você está pensando" que se torna legítimo e simétrico dizer, à continuação, "pois eu estou pensando diferente, e gostaria que você tentasse entender como eu estou pensando". Quer dizer, o que se aprende (ou o que se internaliza, no sentido de Vygotsky) não são conteúdos, técnicas, regras, e sim legitimidades. O que se aprende é a legitimidade de certos modos de produção de significados.

Um exemplo que Lins (2006) apresenta para ilustrar sua discussão a respeito da MPM diz respeito a uma licencianda que já atuava em sala de aula e que não entendia o que seus alunos faziam em uma determinada tarefa. A professora ditava números e pedia para os alunos escreverem. Porém, eles escreviam algo muito diferente do que ela esperava. Seguem alguns exemplos:

Quadro 1 - Ditado e escrita

\section{O que a professora ditava $\quad$ O que os alunos escreviam}




\begin{tabular}{|c|c|}
\hline Mil duzentos e trinta e cinco & 1000200305 \\
\hline Dois mil seiscentos e dezenove & 200060019 \\
\hline Três mil e doze & 300012 \\
\hline
\end{tabular}

Fonte: Lins (2006)

Lins (2006) nos conta em seu artigo que essa licencianda chegou totalmente perdida para conversar com ele. Depois de ela explicar o que estava acontecendo, Lins disse que talvez os alunos estavam escrevendo palavras com dígitos e que a partir disso, a professora logo entendeu o que seus alunos faziam. A questão que Lins explicita é que essa professora estava lendo seus alunos por meio de significados matemáticos, pela dicotomia de certo e errado, o que dificultou uma leitura de como eles operavam.

Os alunos falam por meio de significados matemáticos e não matemáticos. É necessário lêlos tentando entender as lógicas que eles operam. Quando um aluno produz significado e mostra sua produção, este acredita ter respondido a uma demanda colocada. Ele não enuncia de qualquer modo, mas em uma direção. Quando o aluno fala na direção do professor é bem possível que use diferentes exemplos e palavras do que quando ele fala na direção de colega de classe. Disso, ressaltamos que os processos de produção de significados são sempre dinâmicos e locais. Assim, uma estratégia seja sempre colocar os alunos para falarem, tentando ler suas singularidades e os modos como falam e agem em sala.

Para darmos continuidade em nossa discussão, acreditamos que é preciso apresentar algumas noções do MCS, tais como significado, objetos, interlocutor, leitura plausível que estão relacionadas à MPM e que já foram movimentadas nesse texto ${ }^{1}$.

Lins (2012, p. 20) caracteriza a noção de significado sendo “[...] aquilo que efetivamente se diz a respeito de um objeto, no interior de uma atividade”. Esta noção esta atrelada a noção de objeto que

[...] são constituídos enquanto tal precisamente pela produção de significados para eles. Não se trata de ali estão os objetos e aqui estou eu, para a partir daí eu descobrir seus significados; ao contrário, eu me constituo enquanto ser cognitivo através da produção de significados que realizo, ao mesmo tempo em que constituo objetos através destas enunciações. (LINS, 1999, p. 86)

Deste modo, produzimos significados e constituímos objetos em uma direção, que Lins caracteriza como interlocutor. Segundo Lins (2012, p. 19),

quando falo na direção de um interlocutor é porque acredito que este interlocutor diria o que estou dizendo e aceitaria/adotaria a justificação que me autoriza dizer o que estou dizendo.

\footnotetext{
${ }^{1}$ Não desdobraremos exemplificações dessas noções. Para mais informações consultar Lins (1999, 2012).
} 
Essas três noções (objeto, significado e interlocutor) contribuem significativamente para o professor ler como seus alunos operam, quais objetos e significados são produzidos em diálogos e produções escritas.

A caracterização da MPM traz elementos que permitem aproximar professores e alunos nos processos de ensino e de aprendizagem, indo em direção ao que foi produzido. A MPM não toma como referência um juízo de valor sobre o que é produzido, mas oferece a possibilidade de realizar leituras que não sejam pela falta. Não se trata de mostrar o que está errado ou mesmo o que o aluno deveria ter feito, mas sim de tentar ler o que ele fez. Disso, segue uma quarta noção que contribui para nossa demarcação da MPM. Trata-se da leitura plausível, um movimento de tentar ler o outro. Segundo Lins (1999, p. 93), “[...] toda tentativa de se entender um autor deve passar pelo esforço de olhar o mundo com os olhos do autor, de usar os termos que ele usa de uma forma que torne o todo de seu texto plausível".

Diante disso e de maneira sucinta, parte do trabalho do professor que ensina matemática é ler seus alunos, os modos como eles operam, e ampliar seus processos de produção de significados. Ler os significados que os alunos produzem e os objetos que constituem em uma direção é uma tarefa complexa que exige repertório e disposição para estar junto com o outro, neste caso o aluno.

A Matemática do Professor de Matemática, então, se configura como um processo no qual significados matemáticos e não matemáticos são produzidos, tendo a interação entre alunos e professores e as leituras que os professores fazem de seus alunos aspectos centrais.

\section{Processos de Produção de significados matemáticos e não matemáticos}

Apresentamos três exemplos exemplares para alguns desdobramentos da noção da MPM. Esses exemplos foram retirados de trabalhos que se relacionam com nossa discussão.

\section{Perguntando aos meus alunos}

O primeiro exemplo, retirado de Santos (2015), trata-se de uma situação em que o aluno explica para o professor como realizou a resolução de um problema. Segue o enunciado do problema:

Quadro 2 - Enunciado do Problema

Estava indo para casa e resolvi levar lanche.

Tinha na carteira $R \$ 10,00$, então comecei a fazer contas:

- Se eu comprar um refrigerante e dois salgados, pagarei $R \$ 7,25$;

- Se eu comprar três salgados e um refrigerante, pagarei $R \$ 9,75$;

- Se eu comprar dois salgados e dois refrigerantes, pagarei $R \$ 9,50$.

Qual o preço de um salgado e um refrigerante?

Fonte: Santos (2015) 
Quando o professor elaborou o problema, imaginou que seus alunos iriam considerar o mesmo salgado e o mesmo refrigerante. Todavia, quando realizou a leitura da produção de significados de seus alunos, na tentativa de entender como eles operaram, percebeu que a maioria agiu como se estivesse em uma padaria, em uma situação com possibilidade de compra. Assim, os alunos atribuíam preço distinto para o salgado e o refrigerante em cada possibilidade. Em diálogo com os alunos, o professor percebeu que eles resolveram o problema atribuindo preços reais aos salgados e refrigerantes, tomando como referência o mercado do bairro onde moram. Se no mercado há salgados e refrigerantes de tamanhos distintos, logo os preços também são distintos.

Este exemplo evidencia uma mudança de perspectiva do professor, colocando-se na possibilidade de dar legitimidade aos aspectos matemáticos e não matemáticos que permeiam as produções dos alunos.

\section{O problema das jujubas}

O segundo exemplo (SANTOS, 2015) trata de uma discussão que ocorreu em um Grupo de Trabalho com professores de matemática. Em um dos encontros, discutimos problemas matemáticos que são corriqueiros na vida dos professores, problemas de livros didáticos. Segue, então, o problema que uma professora apresentou para os colegas do grupo.

Figura 1 - Problema das Jujubas.

\section{Um pacote continha 24 jujubas. Ari co- meu um terço, Lia comeu um quarto e Maria, um sexto. \\ a) Quantas jujubas comeu cada um deles? \\ b) Será que restou um terço das jujubas no pacote? Năo, pois $\frac{1}{3}$ de 24 é 8 , e no pacote sobraram apenas}

Fonte: Santos (2015)

Durante as discussões no grupo e por meio de análise de produções escritas de alunos em relação ao item "a", os professores identificaram que algumas respostas não condiziam com a resposta do livro. Uma resposta apresentada considerava 8 jujubas para a primeira pessoa (um terço de 24), 4 para segunda (um quarto de 16) e 2 para terceira (um sexto de 12). Para outros alunos, deveria ser 8 para a primeira pessoa, 6 para segunda e 4 para terceira, em acordo com a resposta do 
livro. O que torna isto interessante é o fato de que, para a maioria dos professores, a primeira resposta não tinha coerência, pois os alunos cometeram um erro de interpretação. Para dois professores, o modo como o aluno compreendeu a situação era plausível e eles identificam a estratégia como possibilidade para "atacar" este tipo de problema. Sustentaram sua posição explicando que ao entregar 8 jujubas para primeira pessoa, ao encontrar a segunda, o pacote continha 16 jujubas e não mais 24. Para outros, o cálculo era simples e direto, preso à matemática do matemático.

É notório que o primeiro grupo de professores leu a produção dos alunos por meio do conceito de fração equivalente, desqualificando o que diverge deste modo de operar, tendo o conteúdo matemático como convergência de pensamentos dos alunos. O segundo grupo de professores reconheceu as diferentes formas de resolução dos alunos e acreditou nesse modo particular e idiossincrático dos alunos como potencialidade de ampliar suas produções de significados.

Os alunos na segunda resposta operaram como se tivessem um saco de jujubas que em cada momento, um colega comeu certa quantidade. Eles tomaram o enunciado do problema em meio a processos de produção de significados da rua (LINS; GIMENEZ, 1997), em situações familiares a eles.

\section{Uma simples divisão}

O terceiro exemplo, construído em situações de sala de aula, tendo o primeiro autor deste artigo como professor, apresenta produções de significados de alunos para uma simples divisão. Segue o enunciado:

Quadro 3 - Enunciado

Quanto é $R \$ 135,00$ dividido entre 5 pessoas?

Fonte: Santos (2015).

A intenção do professor foi produzir juntos com os alunos maneiras de resolver essa atividade, em um primeiro momento por suas resoluções e em um segundo pelos diálogos com os alunos. Diante dessas resoluções e dos diálogos, produzimos uma leitura plausível não apenas do ponto de vista dos conteúdos matemáticos (formais), mas sim do ponto de vista dos processos de produção de significados. Seguem algumas resoluções dos alunos e nossas leituras. 
Figura 2 - Resolução de Wilian²

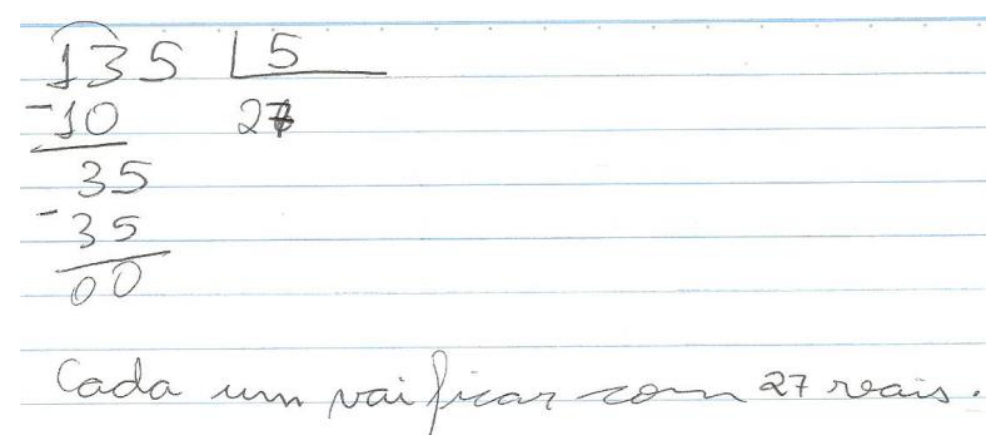

Fonte: Acervo dos autores.

Wilian apresenta domínio do procedimento para resolver essa divisão, utilizando uma estratégia usual de sala de aula. Todo seu processo envolve as operações usuais, aplicando a matemática formal para resolver a atividade. Focando no modo como organiza a produção, Wilian considera as relações de centena, dezena e unidade. Se olharmos apenas para a produção escrita de Wilian, não é possível identificar se ele apenas aprendeu e replica o processo, ou se compreende que o número 13 equivale a 13 dezenas. Em um diálogo com Wilian, percebemos que ele apenas aplica um procedimento para resolver a atividade e que para ele o número 13 corresponde ao número 13 e não a 13 dezenas.

Destacamos com essa produção que muitas vezes a maneira tomada como "correta" ao resolver um problema matemático, "esconde" certos modos de os alunos operarem. Questionar os alunos, problematizar seu modo de resolução e pedir a eles justificações sobre seus processos também devem fazer parte das estratégias pedagógicas dos professores, mesmo quando os alunos, aparentemente, produzem suas resoluções "corretas". Neste caso específico, aparentemente, esse aluno resolve e compreende os procedimentos deste conteúdo matemático. Apenas, aparentemente.

Figura 3 - Resolução de Gustavo

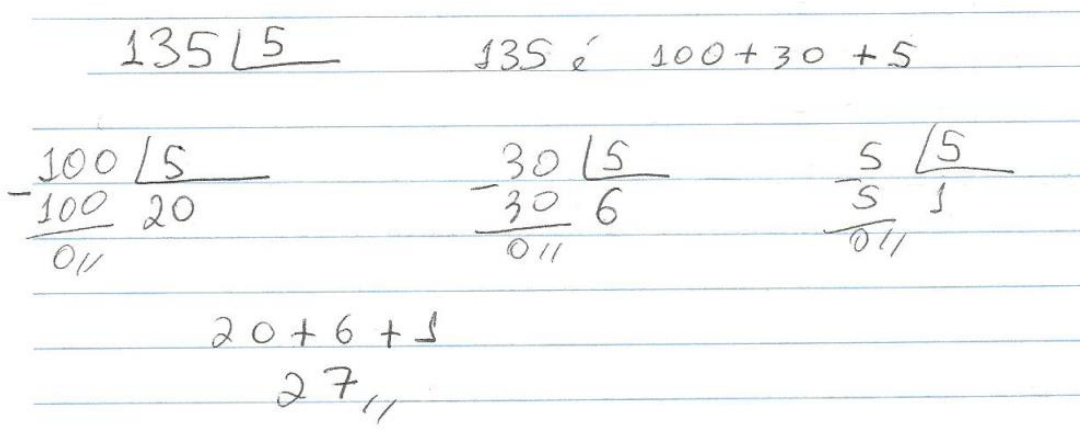

Fonte: Acervo dos autores.

\footnotetext{
${ }^{2}$ Os nomes dos alunos são fictícios para preservar suas identidades.
} 
Gustavo faz três divisões para resolver a atividade. Para ele, 135 é dividido em uma centena, três dezenas e cinco unidades. Logo, ele divide cada um desses números por 5. Depois, ele soma os quocientes e apresenta a resposta. Gustavo tem um repertório detalhado do funcionamento dos processos que envolvem a divisão, sendo que "desmonta" seu processo de resolução em diferentes partes. Em um diálogo com Gustavo ele explica seu processo de resolução e mostra clareza de como pode operar para resolver esse problema.

Figura 4 - Resolução de Alexandre

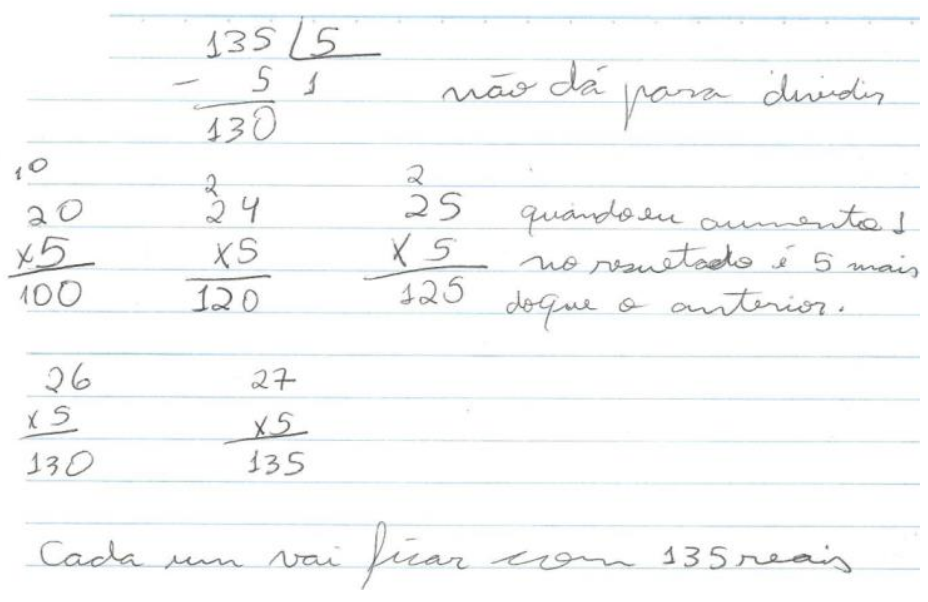

Fonte: Acervo dos autores.

Alexandre inicia a divisão pelo método da chave, tentando envolver a unidade que compõe o número 135, depois a dezena, logo a centena (aparentemente ele resolve da direita para a esquerda). Porém, ao chegar em 130, desiste sua ideia inicial e escreve: não dá para dividir. Diante de uma impossibilidade, Alexandre tentou outra estratégia: que número multiplicado por 5 resulta em 135? Logo, basta multiplicar por 5 vários valores até encontrar 135, sendo este o resultado do problema. Durante seu procedimento percebe uma regularidade: ao entregar um real para cada pessoa, aumenta 5 no total.

Ao olharmos para resposta do aluno, mesmo encontrando 27 em seus cálculos, vemos que ele apresenta: Cada um vai ficar com 135 reais. Ao dialogarmos com Gustavo, ele explica o que havia feito e que em sua resolução trocou os valores. Logo, ao constatar isso, ele corrige sua resposta, dando um sorriso maroto.

Apesar das estratégias de Wilian, Gustavo e Alexandre se enquadrarem no mesmo conteúdo matemático, uma simples divisão, os significados que eles produzem e o modo como operam suas justificações são muito diferentes. Acreditamos que cada um deles resolveu uma atividade diferente. Wilian aplica um procedimento passo a passo que acredita levá-lo à resposta correta. Suas justificações são na direção de seguir os passos. Gustavo conhece propriedades dos 
números naturais e constrói três divisões, cujo resultados somados resolvem o problema. Alexandre, por outro lado, resolve multiplicações em tentativas de encontrar um número que multiplicado por 5 resulta em 135 .

Do ponto de vista de conteúdos, os três resolveram um exercício de divisão. Porém, do ponto de vista da produção de significados cada um deles resolveu uma atividade muito diferente.

Ao olharmos para os três exemplos exemplares que apresentamos, notamos que a MPM permite potencializar os processos de leituras, interação e diálogo entre professores e alunos, saber "onde" os alunos estão e que para eles não falta coisa alguma, pois falam e produzem de um modo. Lê-los não buscando o que eles deveriam fazer em função do que eles fizeram, mas sim tentando se colocar em seus "lugares". Interagir com eles em meio a perguntas que instigam falarem e explicarem seus processos de resoluções das atividades, por meio de significados matemáticos e não matemáticos.

Quem a sabe, então, seja possível intervir nos seus processos de produção de significados com o intuito de ampliá-los; não descartá-los, nem mesmo construir uma valoração entre corretos, parcialmente corretos e incorretos; ampliá-los em modos de organizar seus modos de lidar com situações escolares.

No mercado de meu bairro cada salgado e refrigerante tem preços diferentes, pelo simples fato de serem diferentes (primeiro exemplo exemplar). Se eu tenho um saco de jujubas e cada colega pega uma quantidade, um de cada vez, minhas balas vão diminuindo e deste modo minhas contas são diferentes (segundo exemplo exemplar). Professor, aqui é uma simples divisão, é só aplicar o passo a passo. (FALA DE WILIAN)

Nada disso professor, aqui eu vou "separar" o número, "desmontá-lo", pois com números menores eu sei fazer a continha. (FALA DE GUSTAVO)

Professor eu acho que nesse caso eu não sei dividir, então eu vou multiplicar para resolver esse exercício. Dá certo também e funciona, funciona mesmo (terceiro exemplo exemplar). (FALA DE ALEXANDRE)

Essas falas são significados de alunos ao resolverem certas atividades, com significados matemáticos e não matemáticos. Precisamos, como professores, levá-las em conta para dialogar com os alunos e construir interações produtivas.

\section{Parte 3: Considerações em relação à prática do professor que ensina matemática.}

Uma importante consideração é a necessidade de os professores construírem repertórios para ler os processos de produção de significados de seus alunos, construir repertórios em espaços formativos, em conversas com os colegas, na leitura atenta de como seus alunos operam em sala de aula. Muitas vezes, os alunos constroem suas resoluções produzindo significados que fazem parte do seu 
cotidiano, e que não seguem a lógica da matemática escolar (como mostramos em nossos três exemplos). Este artigo apresenta alguns elementos para construção desses repertórios.

Um modo de organizar as propostas de trabalho e toda a dinâmica de sala de aula é a de pensar em produzir/construir para os alunos: os professores de um lado e os alunos de outro. Nesse espaço, o professor gerencia, organiza e constrói para os alunos, controlando suas ações e seus processos de produção de significados. Os erros dos alunos devem ser corrigidos, pois a ideia central é que eles cheguem ao resultado correto. Também eles podem fazer parte do processo, porém em uma leitura do professor para a atividade matemática do aluno por meio da falta: esse aluno sabe isso, mas ainda falta aquilo. Essa seria uma sala de aula pautada no ensino de conteúdos.

Outro modo de organizar as propostas de trabalho e toda a dinâmica de sala de aula é a de pensar em produzir/construir com os alunos: os professores e alunos estão do mesmo lado. Nesse espaço, alunos e professores gerenciam, organizam e constroem juntos seus processos, suas aprendizagens, suas desaprendizagens. $\mathrm{O}$ erro e a falta não fazem muito sentido nessa abordagem, pois professores e alunos estão juntos problematizando processos que envolvem significados matemáticos e não matemáticos. Essa seria uma sala de aula pautada em aprendizagens, em ampliar modos de produzir significados.

Nosso convite, então, é de construirmos nossas práticas profissionais com os alunos, com seus modos idiossincráticos de lidar com as situações escolares.

A Matemática do Professor de Matemática oferece elementos que permitem ao professor que ensina matemática ter uma interação produtiva com seu aluno a partir do que engendrou como estratégia de resolução de problemas, bem como possibilidades de ampliar seu repertório e seus modos de construir mundos. Sua potencialidade está em tomar como legítimo o modo como os alunos falam e agem. É fundamental que seja desenvolvida a potencialidade do professor em realizar a leitura do que produz seus alunos, do que é dito no interior de uma atividade, de cada situação. Aceitar a existência da Matemática do Professor de Matemática é criar possibilidades de discutir aspectos que envolvem significados matemáticos e não matemáticos que fazem parte das interações.

Na conjuntura como a escola e a sala de aula são organizadas, há entraves que certamente dificultam o desenvolvimento de uma prática profissional de professores que ensinam matemática sob a ótica da Matemática do Professor de Matemática. Talvez, a ideia seja começar em situações singulares, construindo, por exemplo, debates e diálogos entre alunos nos quais eles explicitem seus diferentes modos de produzir significados, ou mesmo colocando-os em atividades nas quais eles 
"analisem" produção de significados de seus colegas. Nossa discussão não é na direção de totalidades, mas sim de possibilidades, sempre em microespaços.

Como nos anos iniciais do Ensino Fundamental, os alunos (ainda) não foram capturados pelos processos de homogeneização da escola, ainda não foram adestrados a responder perguntas do modo como o professor quer ouvir, eles constroem estratégias muito interessantes e criativas. Com isso, é possível pensar em uma educação matemática que potencialize e amplie seus processos de produção de signficados. A Matemática do Professor de Matemática tem essa potencialidade, na direção de: ler os processos de produção de significados matemáticos e não matemáticos dos alunos; interagir e intervir nos modos como eles operam; explicitar diferenças e diferentes significados produzidos por eles; tematizar e ampliar outros modos de produzir significados. Como Lins (2006) afirma, “[...] o centro está na capacidade de leitura do professor, que é direcionada para os alunos -, e não para restringir ao conteúdo (LINS, 2006, p. 13, tradução nossa)”.

\section{Referências}

BALL, D. L.; BASS, H. Toward practice-based theory of mathematical knowledge for teaching. In: B. Davis.; E. Smith (Eds). Proceedings of the 2002 Annual Meeting of the Canadian Mathematics Education Study Group, Edmonton, 2003. Edmonton. Proceedings... Edmonton: CMESG/GCEDM, 2003, p. 3-14.

BALL, D.; THAMES, M. H.; PHELPS, G. C. Content Knowledge for Teaching: What make it special? Journal of Teacher Education, v. 59, n. 5, p. 389-407, 2008

LINARDI, P. R. Rastros da formação Matemática na prática profissional do professor de matemática. 2006. Tese (Doutorado em Educação Matemática) - Instituto de Geociências e Ciências Exatas, Universidade Estadual Paulista, Rio Claro, 2006.

LINS, R. C. Por que discutir Teoria do Conhecimento é relevante para a Educação Matemática. In: BICUDO, M. A. V. (Org.). Pesquisa em Educação Matemática: Concepções e Perspectivas. Rio Claro: Editora UNESP, 1999. p. 75 - 94.

. Characterizing the mathematics of the mathematics teacher from the point of view of meaning production. In: 10th International Congress on Mathematical Education, Copenhagen, 2006. Copenhagen. Proceedings... Plenary and Regular Lectures, 2006, p. 1-16.

. A diferença como oportunidade para aprender. In: Peres, E. et al. (orgs.). Processos de ensinar e aprender: sujeitos, currículos e cultura: livro 3. Porto Alegre: EDIPUCRS, 2008, p. 530-550.

. Modelo dos Campo Semânticos e Educação Matemática: 20 anos de história. Org. Claudia Laus Angelo [et al.]. São Paulo: Midiograf, 2012.

LINS, R. C. \& GIMENEZ, J. Perspectivas em aritmética e álgebra para o século XXI. Campinas: Papirus, 1997.

MA, L. Saber e Ensinar Matemática Elementar. Lisboa: Gradiva, 2009. 
MOREIRA, P. C. O conhecimento matemático do professor: formação na licenciatura e prática docente na escola básica. 2004. Tese (Doutorado em Educação) - Faculdade de Educação, Universidade Federal de Minas Gerais, Belo Horizonte, 2004.

ROWLAND, T.; HUCKSTEP, P.; THWAITES, A. Elementary teachers' mathematics subject knowledge: the knowledge quartet and the case of Naomi. Journal of Mathematics Teacher Education, New York, v.8, n.3, p. 255-281, 2005

ROWLAND, T. Researching teachers' mathematics disciplinary knowledge. In P. Sullivan and T. Wood (Eds.) International handbook of mathematics teacher education: vol.1. Knowledge and beliefs in mathematics teaching and teaching development. Rotterdam: Sense Publishers, p. 273298, 2008

SANTOS, E. S. Um Long Play Sobre Formação de Professores que Ensinam Matemática. 2016. Dissertação (Mestrado em Educação Matemática) Instituto de Matemática, Universidade Federal de Mato Grosso do Sul, Campo Grande, 2016.

VIOLA DOS SANTOS. Legitimidades possíveis para a Formação Matemática de Professores de Matemática (Ou: Assim falaram Zaratustras: uma tese para todos e para ninguém). 2012. 360p. Tese (Doutorado em Educação Matemática) - Instituto de Geociências e Ciências Exatas, Universidade Estadual Paulista, Rio Claro, 2012.

VIOLA DOS SANTOS, LINS, R. C. Movimentos de Teorizações em Educação Matemática. BOLEMA: Boletim de Educação Matemática (Online), v. 30, p. 325-367, 2016. 